\title{
Dynamic Behavior and Constitutive Model for Two Tantalum-Tungsten Alloys under Elevated Strain Rates
}

\author{
Gao Fei ${ }^{1}$, Zhang Xianfeng ${ }^{1}$, Serjouei Ahmad ${ }^{2}$, Wang Mingyang ${ }^{1}$, Li Lei ${ }^{1}, \quad$ Xiong \\ Wei $^{1}$, Zhang Jiang ${ }^{3}$ \\ ${ }^{1}$ Nanjing University of Science \& Technology, Nanjing 210094, China; ${ }^{2}$ Nanyang Technological University, Singapore 639798; ${ }^{3}$ Ningbo \\ Branch of China Academy of Ordnance Science, Ningbo 315103, China
}

\begin{abstract}
The quasi-static and dynamic deformation behavior of two Ta-W alloys (Ta-2.5W and Ta-10W, mass fraction) was investigated by the quasi-static and dynamic compression test and Split Hopkinson pressure bar (SHPB) and Taylor impact tests. The results show that the yield stress of Ta-W alloys exhibits sensitivity to strain rate and $\mathrm{W}$ content. Based on the quasi-static and high strain-rate experimental data, the material constants in Johnson-Cook (JC) model were obtained for the two Ta-W alloys. In addition, validation of the derived constitutive model was carried out through comparison of Taylor impact inhomogeneous deformations under high strain rate $\left(10^{3} \sim 10^{4} \mathrm{~s}^{-1}\right)$, obtained from simulations with their experimental counterparts. It is shown that the simulation results agree well with post-test geometries in terms of side profiles and impact-interface footprints for Taylor impact tests. To bridge the different spatial scale involved in the process of tantalum-tungsten alloy deformation, a meso-scale research was proposed via optical microscope (OM) image analysis. The results presented in this paper, provide new insights into the mechanisms suitable for the constitutive relations determination process.
\end{abstract}

Key words: tantalum-tungsten alloys; SHPB; dynamic behavior; Taylor impact; constitutive model

Tantalum (Ta) and tantalum-based alloys continue to attract scientific and engineering interests due to their high density, melting point, excellent formability, good heat conductivity, good fracture toughness (even at low temperatures), corrosion resistance, and weldability ${ }^{[1]}$. Based on these characteristics, $\mathrm{Ta}$ and its alloys are widely used in the fields of electron, chemical, aerospace, weapons, etc. ${ }^{[2]}$.

The structure and mechanical properties of Ta and its alloy are markedly influenced by the internal factors such as the content of trace impurity and crystal structure. They have attracted, due to their high sensitivity to the change of temperature and strain rate, the attention of many researchers ${ }^{[3-6]}$. The yield stresses of unalloyed Ta and tantalum-tungsten (Ta-W) alloys, exhibit very high sensitivity to strain rate, while their hardening exponent has been found to be insensitive to strain rate and temperature at low temperatures or at high strain rates [7]. Further experimental and theoretical studies were carried out by $\mathrm{Gray}^{[8]}$ on the influence of strain rate on the substructure evolution in metals and alloys. Zhang et al ${ }^{[9]}$ studied the mechanical properties of several tantalum alloys with higher $\mathrm{W}$ content. They found that the strength and hardness of Ta-W alloys increase linearly with the increase of $\mathrm{W}$ content, and the decline of ductility is not significant with the increase of $\mathrm{W}$ content, implying that the Ta-W alloys have high strength and good plasticity properties. To date, a number of popular strength models have been used to predict the constitutive behavior of tantalum-tungsten alloys over a range of strain rates. The models proposed by Johnson and Cook ${ }^{[10]}$ (JC model), Zerilli and Armstrong ${ }^{[11]}$ (ZA model), and Steinberg et al ${ }^{[12]}$, are among the most widely known and

$\overline{\text { Received date: October 11, }} 2016$

Foundation item: the Zijin Intelligent Program, Nanjing University of Science and Technology (2013_ZJ_0101); Qing Lan Project of Jiangsu Province; State Key Laboratory of Explosion Science and Technology (Beijing Institute of Technology) (KFJJ15-07M)

Corresponding author: Zhang Xianfeng, Ph. D., Professor, School of Mechanical Engineering, Nanjing University of Science \& Technology, Nanjing 210094, P. R. China, E-mail: lynx@mail.njust.edu.cn 
frequently used. A comparative study of the JC and modified JC constitutive relations for Ta was performed by Peng et al ${ }^{[13]}$ and Bai et al ${ }^{[14]}$. Material parameters of the mechanical threshold stress (MTS), JC, and ZA constitutive relations for Ta and Ta-W alloys were derived by Chen and Gray ${ }^{[7]}$. The results of this study substantiate the applicability of these models for describing the high strain-rate deformation of $\mathrm{Ta}$ and Ta-W alloys.

Split Hopkinson pressure bar (SHPB) and Taylor impact techniques have been widely used to measure and validate mechanical properties of metallic materials at high strain-rate. The FE code, ABAQUS/Explicit, used in the current study, allows efficient reproduction of the dynamic loading processes at high speed events ${ }^{[15-17]}$.

Currently, the Taylor test is primarily used in conjunction with numerical simulations as a valuable tool for validating constitutive models of various ductile materials due to the large deformation, large gradients of deformation and stress, unique deformation profiles and high strain rate $\left(10^{3} \mathrm{~s}^{-1}\right)$, which can be achieved in this test. By numerical simulations, Teng et al ${ }^{[18]}$ found three distinct fracture modes for 2024-T351 aluminum alloy and Weldox 406 E steel: the confined fracture inside the cylinder, the shear cracking on the lateral surface and the petalling. Xiao et al ${ }^{[19,20]}$ investigated the effect of projectile hardness on the deformation and fracture behavior of $38 \mathrm{CrSi}$ steel and aluminum alloy 7A04-T6 in the Taylor impact test and simulations. Rakvåg et al ${ }^{[21,22]}$ revealed five distinct deformation and fracture modes in the projectile during Taylor bar impact tests for steel of different hardness values.

Recently, Lopatnikov et al ${ }^{[17]}$ conducted a research to model and simulate dynamic deformation of foam materials during the Taylor cylinder-Hopkinson bar impact experiment, based on the unique non-linear deformation behavior mechanism. However, a systematic study of the complete process from the deformation of quasi-static to their dynamic behavior from elevated strain-rates (SHPB combined with Taylor impact) associated with the simulation of deformation analysis is not yet available in the open literature.

Presented here are quasi-static, SHPB and Taylor impact experimental results for two tantalum-tungsten (Ta-W) alloys, namely Ta-2.5W and Ta-10W alloys. The experimental results are used to develop and validate an empirically-based constitutive relation for the flow stress. In addition, the determined corresponding constitutive parameters of $\mathrm{Ta}-2.5 \mathrm{~W}$ and $\mathrm{Ta}-10 \mathrm{~W}$ are compared. Furthermore, validation of the JC constitutive model is performed through comparison of results obtained from numerical simulations, using ABAQUS, for their experimental SHPB and Taylor impact counterparts. According to the test and simulation results, a good agreement was observed for the post-test geometries in terms of side profiles and impact-interface footprints for
Taylor impact test. With the method of macro-meso incorporation, $\mathrm{OM}$ analyses are used to qualitatively characterize the composition and distribution of constituents as well as the characteristics of deformation surfaces along the longitudinal direction.

\section{Experimental}

\subsection{Quasi-static compression test}

The quasi-static compression tests were conducted using a CSS-44100 Universal Materials Testing Machine with a $300 \mathrm{kN}$ loading capacity. The tests were carried out under displacement control, with a constant cross-head speed of $0.5 \mathrm{~mm} / \mathrm{min}$. This corresponded to a nominal strain rate of $8.3 \times 10^{-4} \mathrm{~s}^{-1}$. The lengths and diameters of the initial and final specimens from each experiment are listed in Table 1. Fig. 1 shows the quasi-static compression test results of four cylindrical specimens, where the compression stress is presented as positive numbers. As depicted in Fig.1, the yield stress varies from $238 \mathrm{MPa}$ (Ta-2.5W) to $550 \mathrm{MPa}$ (Ta-10W) when the $\mathrm{W}$ content varies from $2.5 \%$ to $10 \%$. The stress-strain curves of individual Ta-W alloy specimens are similar in shape; however, the variations in yield stress values are attributed to the variations in W content. With different $\mathrm{W}$ content, the strain hardening behavior is essentially unchanged under low strain rates at room temperature.

\subsection{SHPB compression test}

\subsubsection{Principle of SHPB test}

The SHPB system was used to study the deformation of Ta-2.5W and Ta-10W at high strain-rates, which comprised three bars $14.5 \mathrm{~mm}$ in diameter. The bullet was $300 \mathrm{~mm}$ long and the length of the incident and transmitted bars were both $800 \mathrm{~mm}$. The striker bar was propelled at a specified velocity, hitting the incident bar and causing compression of the specimen. Prior to impact, near the impact area, the velocity was measured using an electronic velocity measurement unit consisting of two pairs of photodiodes and light sources. Strain gauges were used to measure the elastic wave within the bars which were then used to analyze the specimen response. In this study, a method to combine the incident, reflected and transmitted strain pulses was adopted for data analysis of the SHPB experiments.

\subsubsection{SHPB compression test results}

The strain circuit outputs of the incident, reflected and transmitted waves in Ta-W alloys at different strain rates are shown in Fig.2. The left top trace gives the incident pulses and right bottom trace gives the reflected strain pulse. The right top trace gives the transmitted strain pulse. The lengths and diameters of the initial and final specimens from each experiment, and corresponding velocity and strain rate are listed in Table 2

Based on the recorded incident, reflected and transmitted waves, the relationships of the true stress and true strain with 
Table 1 Quasi-static compression test data of Ta-2.5W and Ta-10W alloys (mm)

\begin{tabular}{ccccccc}
\hline \multirow{2}{*}{ Alloy No. } & \multicolumn{2}{c}{ Initial } & & \multicolumn{2}{c}{ Final } \\
\cline { 2 - 3 } \cline { 5 - 6 } & Diameter & Length & & Diameter & Length \\
\hline Ta-2.5W-1\# & 12 & 10 & & 19.4 & 4.5 \\
Ta-2.5W-2\# & 12 & 10 & & 20.8 & 3.7 \\
Ta-10W-3\# & 13 & 10 & & 16.68 & 6.84 \\
Ta-10W-4\# & 13 & 10 & & 16.70 & 6.82 \\
\hline
\end{tabular}

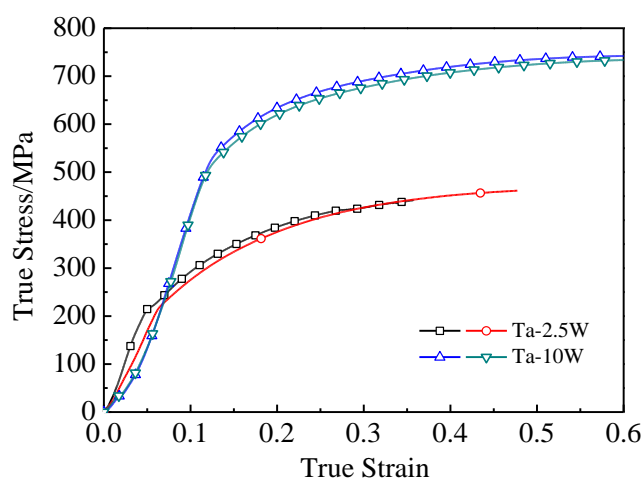

Fig.1 Compression true stress-strain curves of Ta-2.5W and Ta-10W under quasi-static deformation at room temperature

different tungsten contents of Ta-W alloy at elevated strain rates are shown in Fig.3. It can be concluded from the SHPB results that:

(1) Strain rates play a significant role in determining the true stress, $\sigma_{\mathrm{s}}$, and true strain, $\varepsilon_{s}$, relations of Ta-W alloys. Both Ta-2.5W and Ta-10W show a high yield-stress (Fig.3) with increasing of the strain rate. However, plastic deformation capacity decreases as a result of $\mathrm{W}$ content increasing. This can be seen in Fig. $3 \mathrm{a}$ and $3 \mathrm{~b}$, at the similar
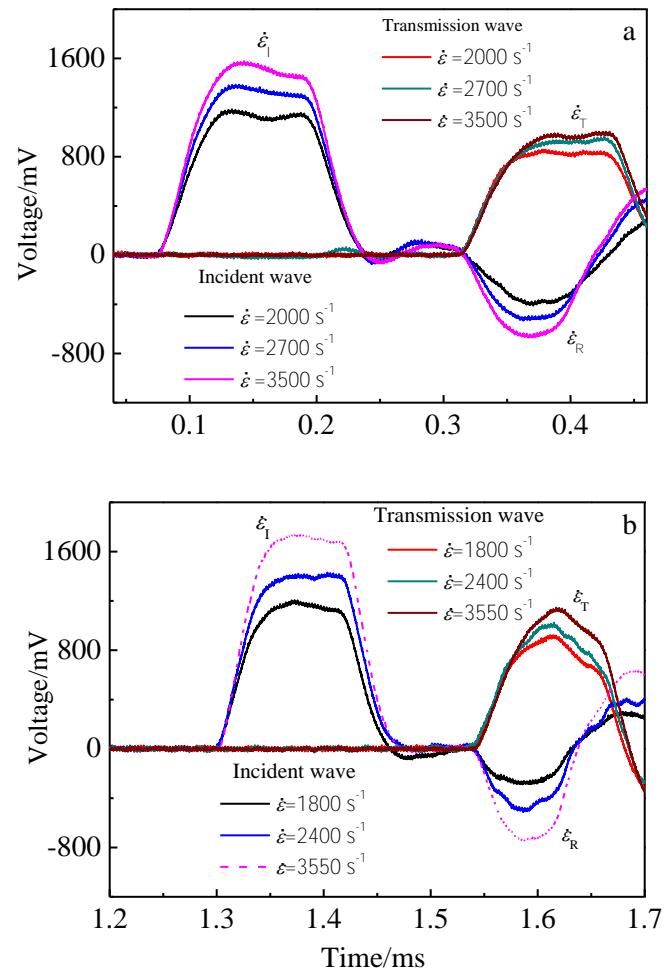

Fig. 2 Strain circuit outputs of the incident, reflected and transmission waves at different strain rates for Ta-2.5W (a) and Ta-10W (b)

strain rate, $3500 \mathrm{~s}^{-1}$ (i.e. $V_{0}=36.76 \mathrm{~m} / \mathrm{s}$ ) and $3550 \mathrm{~s}^{-1}$ (i.e. $V_{0}$ $=39.43 \mathrm{~m} / \mathrm{s}$ ) for $\mathrm{Ta}-2.5 \mathrm{~W}$ and $\mathrm{Ta}-10 \mathrm{~W}$, respectively. Softening behavior begins at strain of 0.24 for Ta-2.5W, while the value is decreased to 0.22 for Ta-10W. A similar behavior is obvious at other strain rate.

(2) At strain rates less than or equal to $1500 \mathrm{~s}^{-1}$ (i.e. $V_{0}=$ $21.32 \mathrm{~m} / \mathrm{s}$ ), the Ta- $2.5 \mathrm{~W}$ exhibits linear elastic deformation

Table 2 SHPB experimental results

\begin{tabular}{|c|c|c|c|c|c|c|}
\hline \multirow{2}{*}{ Shot No. } & \multicolumn{2}{|c|}{ Initial } & \multicolumn{2}{|c|}{ Final } & \multirow{2}{*}{ Velocity $/ \mathrm{m} \cdot \mathrm{s}^{-1}$} & \multirow{2}{*}{ Strain rate $/ \mathrm{s}^{-1}$} \\
\hline & Diameter/mm & Thickness/mm & Diameter/mm & Thickness/mm & & \\
\hline Ta-2.5W-1\# & 12 & 10 & 12.16 & 9.6 & 18.28 & 1150 \\
\hline Ta-2.5W-2\# & 12 & 10 & 12.26 & 9.5 & 21.32 & 1500 \\
\hline Ta-2.5W-3\# & 12 & 10 & 12.65 & 9.3 & 28.77 & 2000 \\
\hline Ta-2.5W-4\# & 12 & 10 & 12.74 & 9.0 & 32.57 & 2700 \\
\hline Ta-2.5W-5\# & 12 & 10 & 13.10 & 8.7 & 36.76 & 3500 \\
\hline Ta-10W-1\# & 10 & 6 & 10.24 & 5.7 & 17.5 & 660 \\
\hline Ta-10W-2\# & 10 & 6 & 10.5 & 5.5 & 25.55 & 1000 \\
\hline Ta-10W-3\# & 10 & 6 & 10.65 & 5.3 & 26.51 & 1800 \\
\hline Ta-10W-4\# & 10 & 6 & 10.9 & 5.1 & 31.81 & 2400 \\
\hline Ta-10W-5\# & 10 & 6 & 11.32 & 4.7 & 37.23 & 3200 \\
\hline Ta-10W-6\# & 10 & 6 & 11.48 & 4.5 & 39.43 & 3550 \\
\hline
\end{tabular}



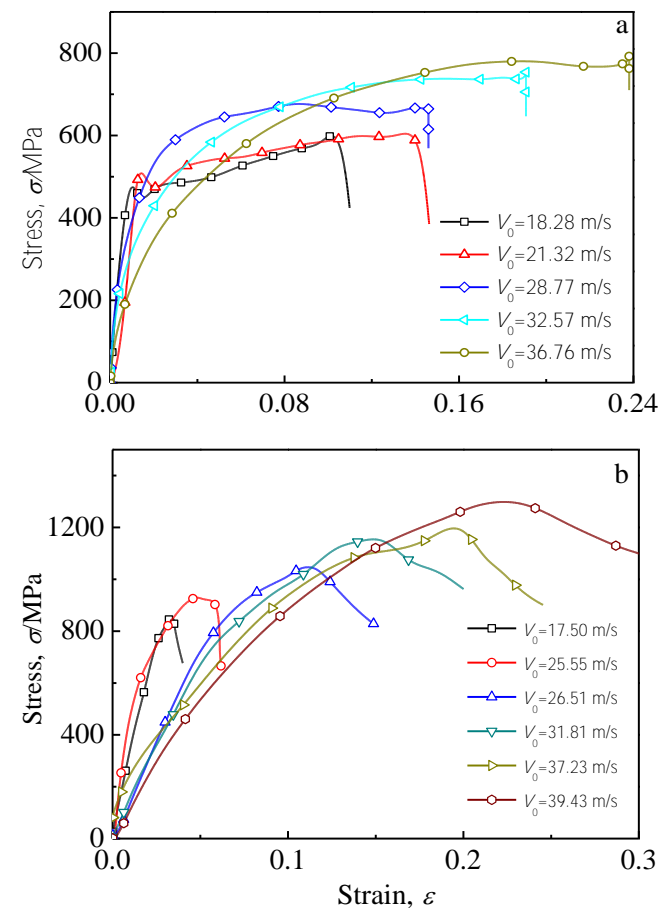

Fig. 3 True stress-true strain for Ta-2.5W (a) and Ta-10W (b)

before a nominal yielding occurs, i.e. there are obvious yielding points. But, the elastic deformations exhibit nonlinear relationship for curves at strain rate above $1500 \mathrm{~s}^{-1}$ which can be attributed to strain rate strengthening effect. However, at both low and high strain rate level, there is no obvious yield stage for Ta-10W. This means that the Ta-W alloys tend to show more brittle or less plastic behavior with increasing of $\mathrm{W}$ content.

For strain rates ranging from $8.3 \times 10^{-4} \mathrm{~s}^{-1}$ to $3.55 \times 10^{3} \mathrm{~s}^{-1}$, in order to investigate the strain rate sensitivity of Ta- $2.5 \mathrm{~W}$ and Ta-10W, Fig.4 shows a collection of the quasi-static and dynamic compression tests data in terms of dynamic yield strength versus strain rate. It can be seen from Fig.4 that a sharp increase of yield strength for Ta- $2.5 \mathrm{~W}$ and Ta-10W are observed approximately above the strain rate $10^{3} \mathrm{~s}^{-1}$.

\subsection{Taylor impact test}

\subsubsection{Experimental set-up}

A one-stage powder gun test facility was used to conduct the Taylor impact tests. The gun mainly consists of a gunpowder pressurized chamber, a $14.5 \mathrm{~mm}$ caliber diameter and $1.5 \mathrm{~m}$ long launch tube, a velocity measurement, and a rigid target. The tube offers a front space to have the initial velocity measure device to be installed. Beyond this, the rigid target and the gun are co-linear and on the same base structure. The striking velocity is controlled by the pressured powder gas. One couple of lasers, placed at the muzzle of the launch tube, is used to trigger the timing device and to get the exit velocities. One set of the lasers for exit velocity measurement was used to trigger the signal. Fig. 5 shows the arrangement of the

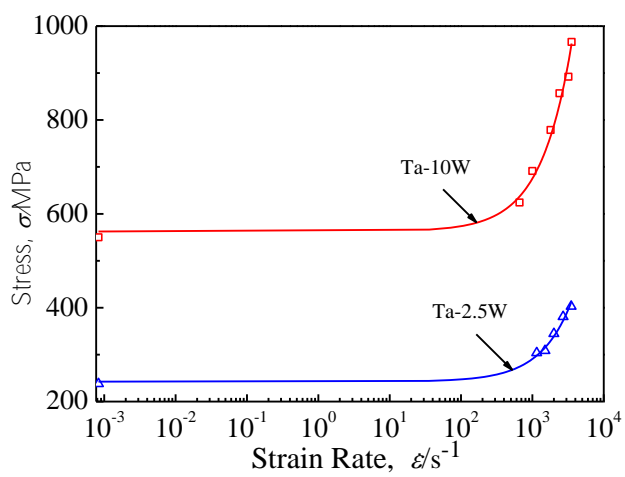

Fig.4 Dynamic yield strength vs. strain rate on logarithmic scale, experimental results for Ta- $2.5 \mathrm{~W}$ and Ta- $10 \mathrm{~W}$

compressed powder gun.

1.3.2 Projectiles and target plate

In this study, the impact tests were performed on cylindrical Ta-W alloy rods. All projectiles were rods of a nominal diameter $D_{\mathrm{i}}=14.5 \mathrm{~mm}$ and a nominal length $L_{\mathrm{i}}=80 \mathrm{~mm}\left(L_{\mathrm{i}} / D_{\mathrm{i}}\right.$ $=5.5$ ).

Other details of the projectiles are listed in Table 3. Dimensional measures used in Table 3 are sketched in Fig.6. To investigate the projectile deformation behavior, target plates were made of hard armor steel in order to minimize their plastic deformation during impact. Nonetheless, small indention was found in target plates. All the targets are cylinders of $\varphi 90 \mathrm{~mm} \times 50$ $\mathrm{mm}$ and HRC hardness of $400 \mathrm{MPa}$.

\subsubsection{Experimental results and analyses}

Structural measurements of the projectiles and the test results are summarized in Table 3. As can be seen in Fig.7, with increasing of striking velocities, primary deformation modes, i.e., mushrooming, were identified in the specimens. These modes are described in the following paragraph.

Mushrooming takes place when a projectile impacts a plate at a relatively low velocity. Immediately upon impact, both elastic waves and plastic waves are generated at the impact interface. They propagate and reflect from the tip to the back of the projectile, resulting in its deceleration and deformation. The front part of the projectile bulges out due to the target blocking in the axial direction and unconfined deformation in the transverse direction, while the rear part keeps almost undeformed (Fig.7).

Mushrooming deformation was found in impacts at all striking velocities for the Ta-2.5W and Ta-10W projectiles. Fig.7 shows the deformed projectiles recovered from the tests. From Fig.7, it can be seen that a projectile suffers from axisymmetrical deformation when it impacts a target normally.

Although thick hard armor steel plates were used as targets, small penetration was found in some tests. For Ta-2.5W projectiles, an indentation was found for impact at $V_{0}=111.1$ $\mathrm{m} / \mathrm{s}$ while no visible indentation was found in the other shots ( $V_{0}=72.8$ and $\left.V_{0}=103.4 \mathrm{~m} / \mathrm{s}\right)$. On the contrary, the impact of 


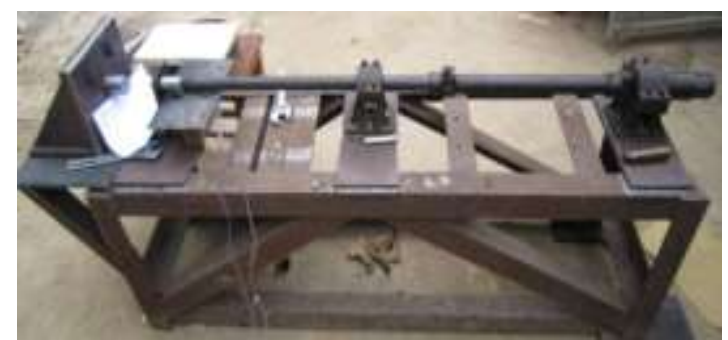

Fig.5 Arrangement of the Taylor impact tests setup

Table 3 Measures of the projectiles and the test results

\begin{tabular}{ccccc}
\hline Shot No. & $V_{0} / \mathrm{m} \cdot \mathrm{s}^{-1}$ & $L_{\mathrm{f}} / \mathrm{mm}$ & $D_{\mathrm{f}} / \mathrm{mm}$ & $L_{\mathrm{und}} / \mathrm{mm}$ \\
\hline Ta-2.5W-1\# & 72.8 & 75.1 & 16.8 & 33.5 \\
Ta-2.5W-2\# & 103.4 & 72.0 & 18.2 & 29.2 \\
Ta-2.5W-3\# & 111.1 & 71.0 & 19.0 & 26.8 \\
Ta-2.5W-4\# & 121.3 & 68.9 & 19.8 & 24.2 \\
Ta-2.5W-5\# & 134.3 & 67.8 & 20.6 & 23.8 \\
Ta-10W-1\# & 70 & 76.8 & 16.8 & 50.5 \\
Ta-10W-2\# & 103.4 & 74.1 & 18.5 & 44.1 \\
Ta-10W-3\# & 128.2 & 72.4 & 19.4 & 33.0 \\
Ta-10W-4\# & 202.4 & 65.9 & 23.8 & 31.1 \\
Ta-10W-5\# & 250.1 & 62.7 & 26.8 & 24.0 \\
\hline
\end{tabular}

$L_{\mathrm{f}}$ : final length; $D_{\mathrm{f}}$ : final diameter; $L_{\mathrm{unc}}$ : unchanged length

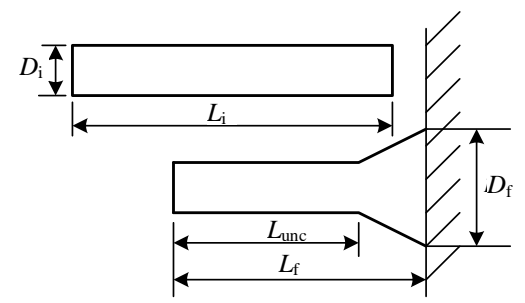

Fig. 6 Dimensional measures used in Table 3 for the undeformed and deformed specimen $\left(D_{\mathrm{i}}\right.$ : initial diameter; $L_{\mathrm{i}}$ : initial length)

Ta-10W projectiles at $V_{0}=103.4 \mathrm{~m} / \mathrm{s}$ resulted in an indentation. Thus, the target deformation magnitude greatly depends on the projectile strength. Fig.8 depicts an example showing a comparison between Ta-2.5W and Ta-10W projectiles deformation. As can be seen, the mushroomed projectiles head consisted of two parts, an inner circle (dashed) and an outer loop (solid). Careful measurements show that the diameter of the inner circle is a little larger than that of the original projectile. This finding is in agreement with previous observations by Chen et al ${ }^{[23]}$ and Xiao et al ${ }^{[19]}$.

\subsubsection{Metallographic analyses}

The top (mark a), center (mark b) and bottom (mark c) surfaces of the recovered $\mathrm{Ta}-2.5 \mathrm{~W}$ projectiles were carefully examined by optical microscope (OM), as shown in Fig.9A.
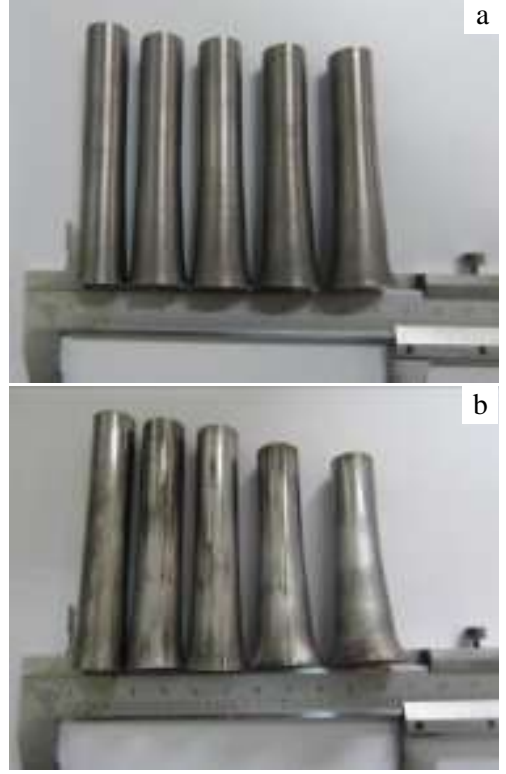

Fig.7 Mushroomed projectiles Ta-2.5W (a) and Ta-10W (b), after corresponding shot No.1\# to No.5\# from left to right

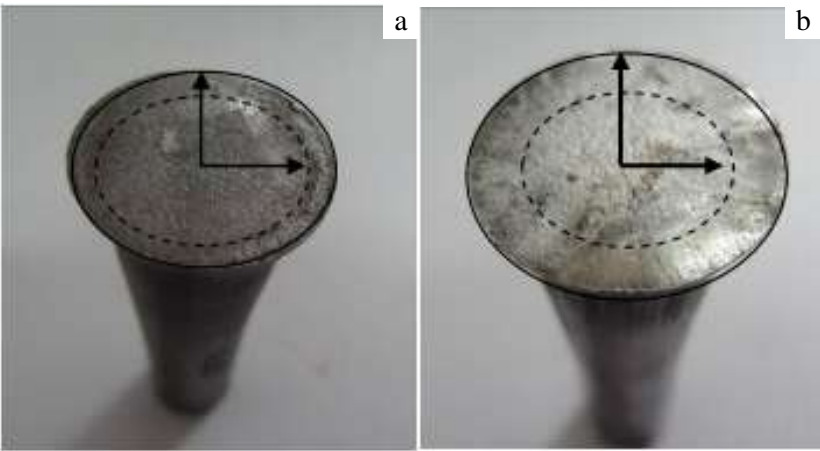

Fig. 8 Projectiles head deformation after Taylor impact for Ta-2.5W -4\# (a) and Ta-10W-3\# (b)

For this, three samples of the deformed Ta- $2.5 \mathrm{~W}$ were mounted, polished, and then etched in a solution of $40 \% \mathrm{HF}$ and $60 \% \mathrm{H}_{2} \mathrm{O}$ (volume fraction) for about $3 \mathrm{~min}$ before observation.

Microstructure of the Ta-2.5W specimen after Taylor tests at $134.3 \mathrm{~m} / \mathrm{s}$ are shown in Fig.9B. It can be seen from Fig.9B that crystalline grains are longer and narrower at bottom surface than those at center surface, which may be a reason for the larger deformation at impact surface. A few dispersive voids distribute in the crystalline grain at top and center surface and disappear at bottom surface, implying that some voids are compacted at bottom surface of the rod. There are no cracks and adiabatic shear bands in the micrographs due to lower impact velocity and larger deformation ability.

The order of magnitude of the strain-rate increases with rising impact velocity. According to the plastic deformation 
and fracture characteristics, due to higher deformation rate the internal voids of the specimen have not enough time to be compacted, thereby resulting in formation of cracks. Cracks rapidly propagate along grain boundaries under high speed impact condition and accelerate the rate of fracture failure, so the plasticity is reduced and brittleness is increased. For this reason, the projectile exhibits shear cracking and fragmentation with increase in impact velocity. Furthermore, if the alloy is loaded with high strain rate, the plastic work will converts into heat in a short time and results in the adiabatic temperature rise of the material. At the same time, inside the adiabatic shear band, where the highly localized deformation takes place, the temperature rises more sharply.

\section{Parameters determination and discussions of JC model}

\subsection{Fitting of constitutive equation to experimental results}

The JC constitutive equation was fitted to the current experimental data because of its simplicity and availability. The JC model is given by the following equation:

$$
\sigma_{\mathrm{e}}=\left[A+B\left(\varepsilon_{\mathrm{e}}^{\mathrm{p}}\right)^{n}\right]\left[1+C \ln \left(\dot{\varepsilon}^{*}\right)\right]\left[1-T^{* m}\right]
$$

where, $\sigma_{\mathrm{e}}$ is the stress, $\varepsilon_{\mathrm{e}}^{\mathrm{p}}$ is the equivalent plastic strain, $\dot{\varepsilon}^{*}=\dot{\varepsilon}_{\mathrm{e}}^{\mathrm{p}} / \dot{\varepsilon}_{0}$ is the dimensionless plastic strain rates, $\left(\dot{\varepsilon}_{0}=8.3 \times 10^{-4} \mathrm{~s}^{-1}\right.$ is the reference strain rate) and $T^{*}=\left(T-T_{\mathrm{r}}\right) /\left(T_{\mathrm{m}}-T_{\mathrm{r}}\right)$ is the homologous temperature, in which $T_{\mathrm{m}}, T, T_{\mathrm{r}}$ are melting, current, and reference temperatures, respectively, and $A, B, n$, $C$, and $m$ are constants.

To determine the material constants, quasi-static and dynamic test results were used to fit above parameters. The JC model parameters determined for Ta- $2.5 \mathrm{~W}$ and $\mathrm{Ta}-10 \mathrm{~W}$ are

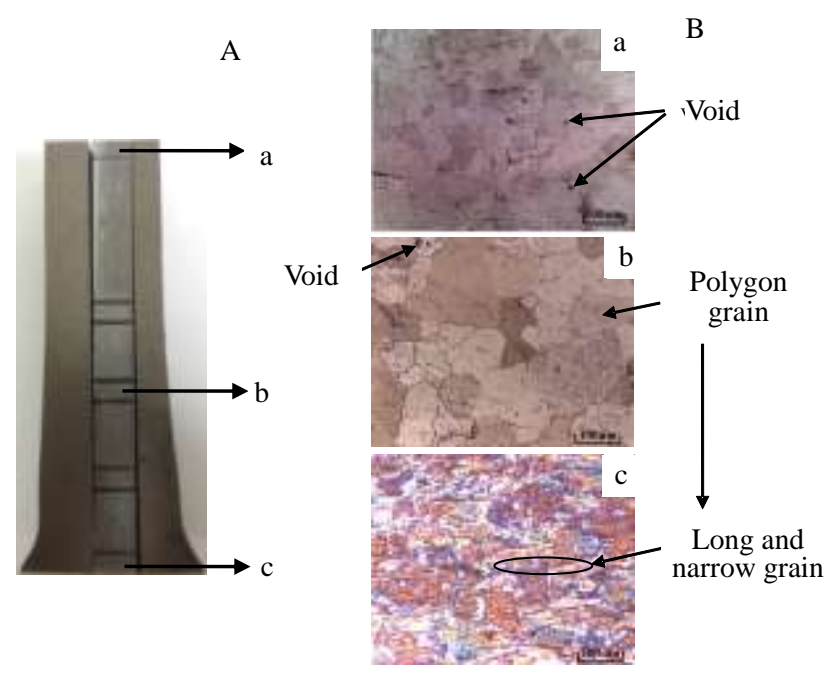

Fig.9 Fragments surface position of recovered Ta-2.5W projectiles (A); OM images of three typical surfaces of Ta- $2.5 \mathrm{~W}$ specimen (B): (a) top, (b) middle, and (c) bottom (impact velocity of $134.3 \mathrm{~m} / \mathrm{s})$ listed in Table 4. The basic approach to fitting the JC model can be found in the work of Brar et al ${ }^{[24]}$.

\subsection{Comparison between Ta-2.5W and Ta-10W}

Constant $A$ is determined from the true stress-true strain data at a strain rate of $8.3 \times 10^{-4} \mathrm{~s}^{-1}$. When Ta is alloyed from $2.5 \mathrm{wt} \% \mathrm{~W}$ to $10 \mathrm{wt} \% \mathrm{~W}$, the yield stress $(A)$ increases from $238 \mathrm{MPa}$ to 550 $\mathrm{MPa}$. This can be attributed to the larger strength of $\mathrm{W}$ compared to $\mathrm{Ta}$, so that with increase of $\mathrm{W}$ content, the dislocations movement would be more difficult, thereby increasing the yield strength. Constants $B$ and $n$ for Ta- $2.5 \mathrm{~W}$ and Ta-10W are determined from the plastic stress-strain data. For Ta-10W, the strain-hardening exponent $n$ is smaller than that of Ta- $2.5 \mathrm{~W}$. Increasing the $\mathrm{W}$ content in Ta-W alloys has a small effect on improving their brittleness. The strain-hardening coefficient $B$ does not have any physical meaning and its will might be increased or decreased with the increase in $\mathrm{W}$ content. Strain rate sensitivity is identified with constant $C$. Increasing the $\mathrm{W}$ content decreases the rate sensitivity of the two Ta alloy, which is consistent with the results of Chen and Gray III ${ }^{[7]}$. Due to the limitations for experimentally varying of the temperature in the laboratory, the temperature softening constant, $m$, was considered as 1 which is a typical value for metallic alloys.

\section{Numerical Simulation of Taylor Impact Test}

The JC constitutive model which describes the high-rate behavior of Ta-W alloy was used as a material model in ABAQUS/Explicit finite element code to simulate several Taylor impact conditions.

\subsection{Computational model}

A 3-D finite element model was built. The geometry of the projectile is a cylinder of $\Phi 14.5 \mathrm{~mm} \times 80 \mathrm{~mm}$ and the target is a cylinder of $\Phi 90 \mathrm{~mm} \times 50 \mathrm{~mm}$, both of which are in close accordance with the dimensions used in the tests (Table 3).

Fig.10 shows the FEM modeling of the projectile and target, which were meshed by eight-node, linear Hex elements with reduced integration (C3D8R) element. An initial $1 \mathrm{~mm}$ gap space between the projectile and the target was specified. A fixed boundary condition in the rear surface of the target plate was applied through a reference point to mimic the text boundary conditions, and the target was modeled as a rigid body, as shown in Fig.11a. The total element number for projectile and target is 484200 and 3340, respectively. As seen in Fig.10, very fine meshes were located in the projectile impact end (30 $\mathrm{mm}$ long) where large deformation develops, while relatively coarse meshes were used in the rare part of the projectile. The minimum element size is $0.25 \mathrm{~mm} \times 0.25$ $\mathrm{mm} \times 0.18 \mathrm{~mm}$ in the projectile. This size is close to that used in the work of Teng et al ${ }^{[18]}$.

The initial load is the projectile impact velocity. The general contact algorithm available in ABAQUS/Explicit with no friction between the contacting parts was used in the calculation. The contact property was defined by the "hard" 
Table 4 Fitting parameters for JC model

\begin{tabular}{ccccccc}
\hline Alloy & $A / \mathrm{MPa}$ & $B / \mathrm{MPa}$ & $n$ & $C$ & $m$ & $T_{\mathrm{m}} / \mathrm{K}$ \\
\hline Ta-2.5W & 238 & 565 & 0.743 & 0.063 & 1 & 3250 \\
Ta-10W & 550 & 380 & 0.618 & 0.049 & 1 & 3250 \\
\hline
\end{tabular}

contact model, which enforces contact constraints using a penalty contact method. Using the computational model stated above, the simulations were carried out for a wide range of impact velocities, $72.8,103.4,134.3 \mathrm{~m} / \mathrm{s}$ for Ta-2.5W, and 128.2, 202.4, $250.1 \mathrm{~m} / \mathrm{s}$ for Ta-10W.

\subsection{Material parameters}

The material parameters used for Ta-2.5W and Ta- $10 \mathrm{~W}$ are listed in Tables 4 and 5. Since there was not any fracture behavior observed in the Taylor tests for the two alloys, failure model was not used in the simulations.

\subsection{Numerical simulation results}

Fig.11a and 11b show the familiar mushroom-like deformation mode of the residual projectiles at $V_{0}=72.8,103.4$, $134.3 \mathrm{~m} / \mathrm{s}$ for Ta-2.5W, $V_{0}=128.2,202.4,250.1 \mathrm{~m} / \mathrm{s}$ for Ta- $10 \mathrm{~W}$, respectively. In these numerical calculations the maximum axial strain rate was only about $2.2 \times 103 \mathrm{~s}^{-1}$. In particular, the initial velocity $V_{0}=72.8 \mathrm{~m} / \mathrm{s}$ for this Ta-W alloys is too small to produce remarkable inelastic deformations which may be helpful in high-strain rate material characterization. A much greater mushrooming effect at the impact face is apparent, especially at $250.1 \mathrm{~m} / \mathrm{s}$.

The deformed specimen lengths and diameters for Ta-2.5W and Ta-10W at different velocities are presented in Table 3, and their comparisons with simulated results are listed in Table 6. In each case, the error between experimental and simulations results is well below $10 \%$, while errors in length, $L_{\mathrm{f}}$, and impact-face diameter, $D_{\mathrm{f}}$, show marginal increase except for $D_{\mathrm{f}}$ at velocity of $250.1 \mathrm{~m} / \mathrm{s}$. Comparison between the experimental and simulated axial strain profiles

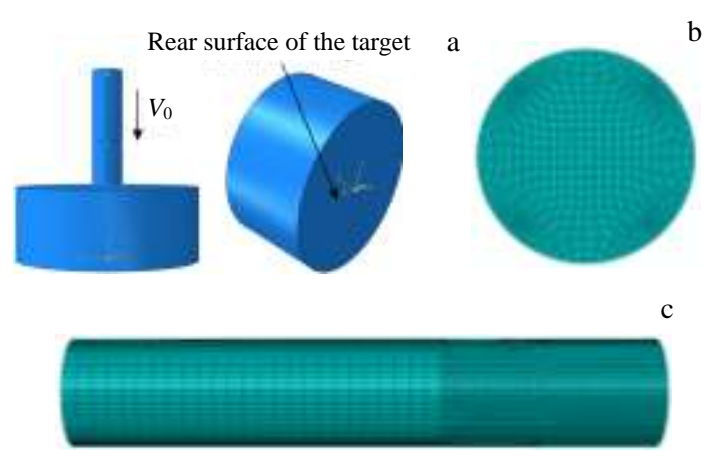

Fig.10 FEM modeling of the Taylor impact tests: (a) projectile target system, (b) mesh of the projectile cross section, and (c) mesh of the projectile in axial direction

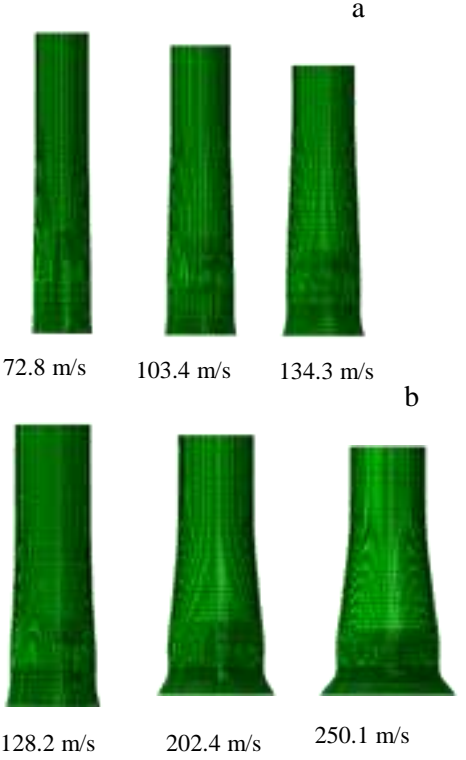

Fig.11 Mushroom-like deformation mode of the residual projectile profiles versus impact velocity: (a) Ta-2.5W and (b) Ta-10W

Table 5 Phisical properties of specimens

\begin{tabular}{cccc}
\hline Specimen & $E / \mathrm{GPa}$ & $\rho / \mathrm{kg} \cdot \mathrm{m}^{-3}$ & $v$ \\
\hline Ta-2.5W & 190 & 16650 & 0.35 \\
Ta-10W & 200 & 17020 & 0.32 \\
\hline
\end{tabular}

along the axes of the post-test specimens are shown in Figs.12 14. Figs 12 and 13 show a comparison between the experimental and simulated profiles along the axes of the post-test specimens at various velocities. The strains along the axes, which are both zero at large height, accumulate at different rates as height decreases. It can be seen that simulation results agree well with experiments. The slight differences between the experimental data and the simulation results are most likely related to the work of plastic deformation converted into heat which were not taken into consideration in the simulations. In addition, the friction effects were neglected in

Table 6 Deformed specimen lengths and diameters $(\mathrm{mm})$

\begin{tabular}{cccccc}
\hline \multirow{2}{*}{ Shot No. } & \multicolumn{2}{c}{ Experiments } & & \multicolumn{2}{c}{ Simulations } \\
\cline { 2 - 3 } \cline { 5 - 6 } & $L_{\mathrm{f}}$ & $D_{\mathrm{f}}$ & & $L_{\mathrm{f}}($ error\% $)$ & $D_{\mathrm{f}}($ error\% $)$ \\
\hline Ta-2.5W-1\# & 75.1 & 16.8 & & $74.8(0.4)$ & $16.3(3.0)$ \\
Ta-2.5W-2\# & 72.0 & 18.2 & & $70.7(1.8)$ & $17.5(3.8)$ \\
Ta-2.5W-5\# & 67.8 & 20.6 & $66.2(2.3)$ & $18.9(8.3)$ \\
Ta-10W-3\# & 72.4 & 19.4 & & $71.6(1.1)$ & $18.3(5.7)$ \\
Ta-10W-4\# & 65.9 & 23.8 & $64.8(1.7)$ & $22.4(5.9)$ \\
Ta-10W-5\# & 62.7 & 26.8 & $61.3(2.2)$ & $25.9(3.4)$ \\
\hline
\end{tabular}



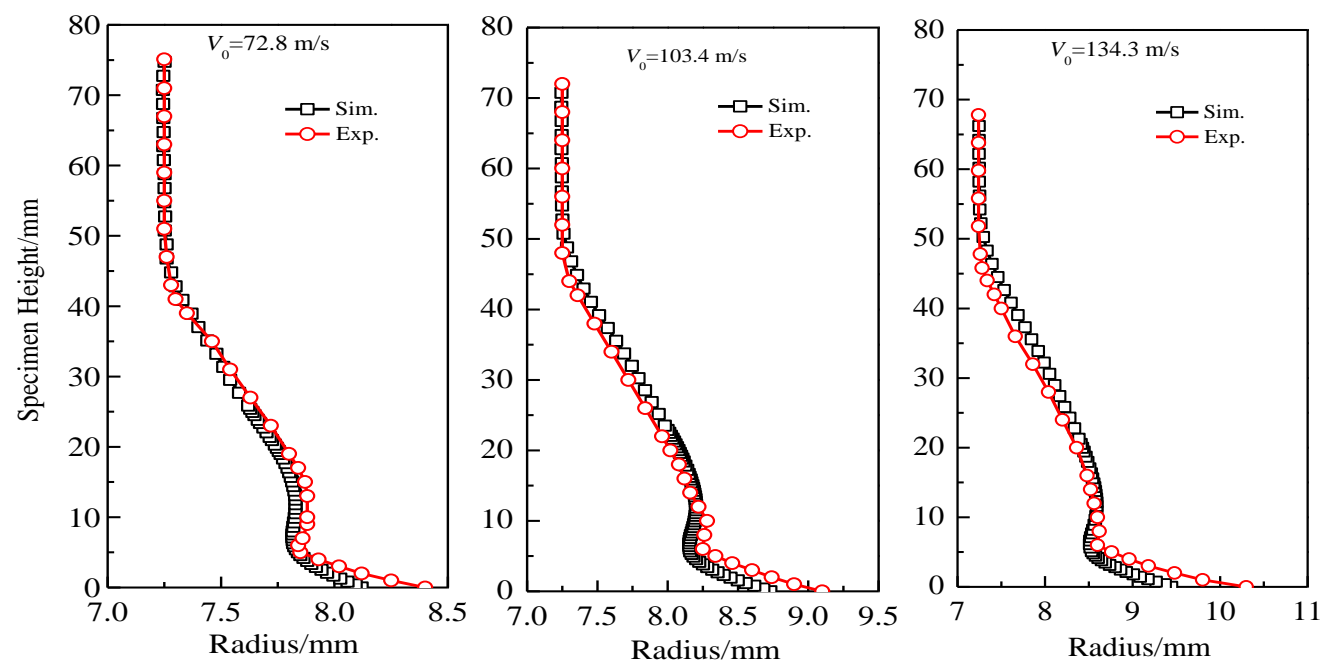

Fig.12 Comparison between the profiles of Ta-2.5W Taylor impact specimens obtained from simulations and experiments at various impact velocities
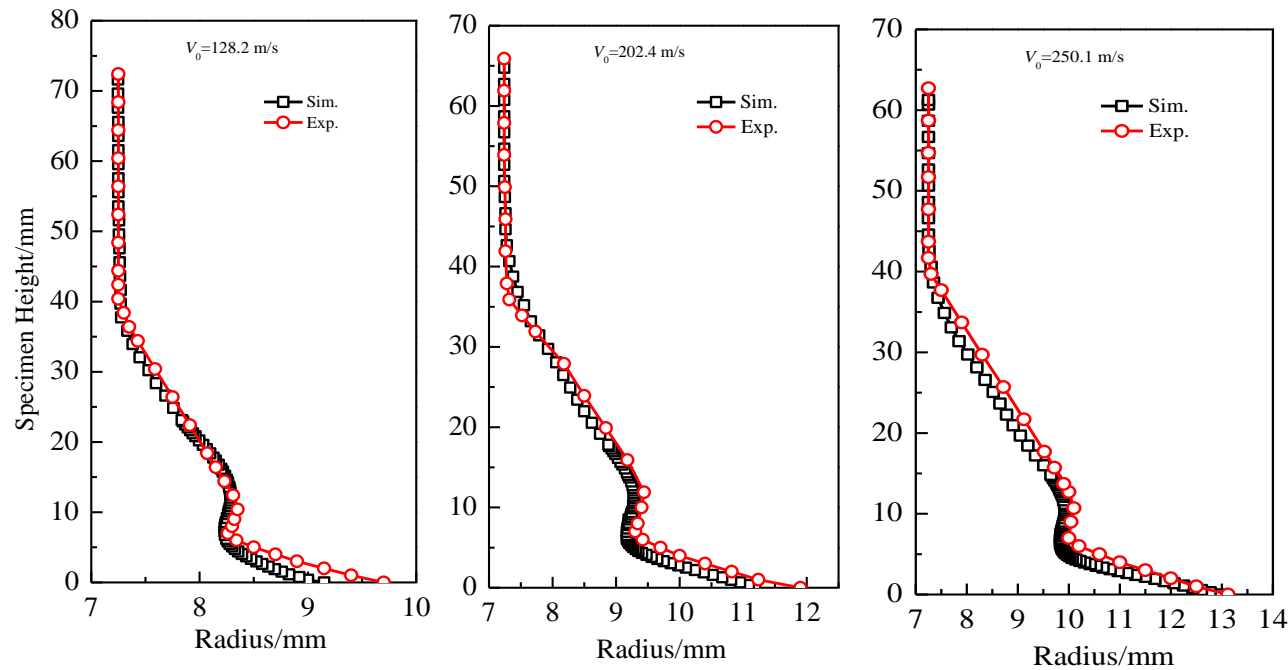

Fig. 13 Comparison between the profiles of Ta-10W Taylor impact specimens obtained from simulations and experiments at various impact velocities

the simulation. This is also the important reason why there exists slight difference between experimental data and simulation results. Fig.14 depicts a visual comparison between the profiles of $\mathrm{Ta}-2.5 \mathrm{~W}$ and Ta-10W specimens obtained from simulations and experiments at close impact velocities (i.e., $134.3 \mathrm{~m} / \mathrm{s}$ for Ta-2.5W and $128.2 \mathrm{~m} / \mathrm{s}$ for Ta-10W). It is evident that with increase in $\mathrm{W}$ content of Ta-W alloys, the deformation resistance increases.

Results from the simulations of the Ta-W projectiles up to the highest impact velocity with mushrooming modes (without any visible fracture) are shown in Fig.15, together with the experimental results from Table 6 . The results are shown as normalized mushroom diameter $D_{\mathrm{f}} / D_{\mathrm{i}}$ and normalized length $L_{\mathrm{f}} / L_{\mathrm{i}}$, where $D_{\mathrm{f}}$ and $L_{\mathrm{f}}$ are the deformed mushroom diameter and length while $D_{\mathrm{i}}$ and $L_{\mathrm{i}}$ are the initial diameter and length of the projectile, respectively. An interesting observation is that the simulations consistently overestimate the shortening of the cylinder and underestimates the mushrooming at the impact end of the projectiles. Similar results were also shown by Rakvåg et al ${ }^{[22]}$ for simulations of unhardened and HRC 40 steel projectiles, and according to the explanations of Rakvåg et al, due to the plastic incompressibility, this indicates that the profile of the projectile is not predicted correctly. Another reason for this discrepancy could be the strain rate sensitivity. 


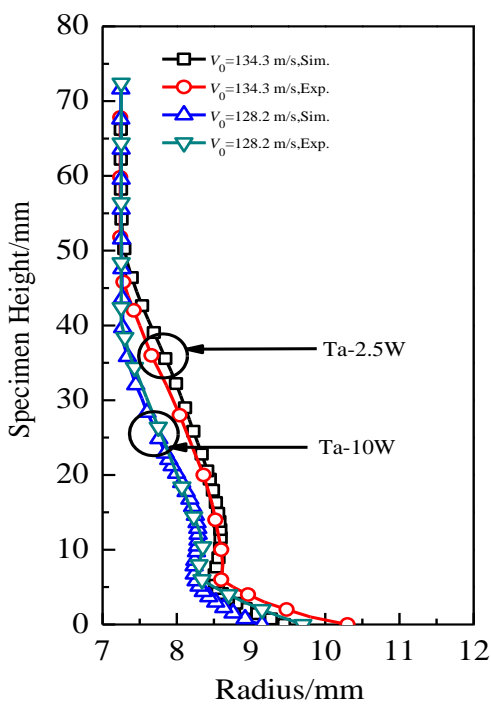

Fig.14 Comparison between the profiles of Ta-2.5W and Ta-10W Taylor impact specimens obtained from simulations and experiments at same impact velocities
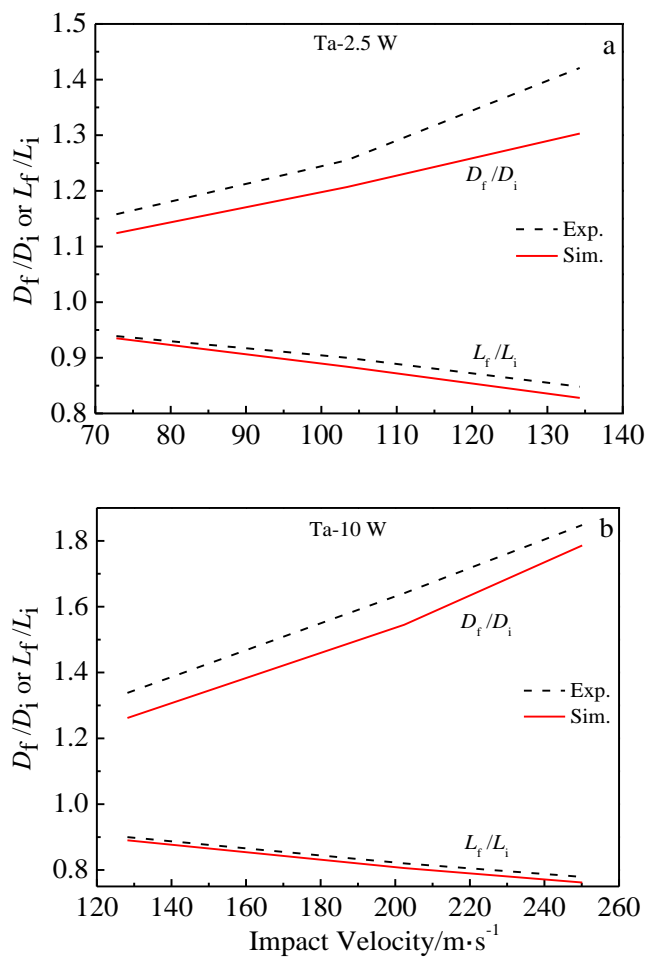

Fig. 15 Comparison between experimental and simulation plastic deformations of the projectiles vs. impact velocity for Ta-2.5W (a) and Ta-10W (b) alloys

\section{Conclusions}

1) Quasi-static compression and SHPB tests are performed on two tantalum-tungsten (Ta-W) alloys, namely Ta-2.5W and Ta-10W and stress-strain curves at different strain rates are obtained. The yield stress of Ta-W alloys exhibits sensitivity to strain rate and $\mathrm{W}$ content, while the hardening exponent in Ta-W alloys is insensitive to those parameters.

2) Based on the quasi-static and SHPB test data, Johnson-Cook (JC) material model constants are determined for the two alloys. Higher $\mathrm{W}$ content results in higher yield strength but smaller strain-hardening exponent and coefficient of strain-rate sensitivity, which is consistent with existing results.

3) Taylor impact experiments are performed to find the dynamic strength and inhomogeneous deformation profile of the two alloys. Mushrooming deformation is found in impacts at all striking velocities for the Ta-2.5W and Ta-10W projectiles, and an inner circle and an outer loop can be seen on the head of the mushroomed projectiles. OM image analysis shows that there are no cracks and adiabatic shear bands are observed in the micrographs.

4) Numerical simulations of the Taylor impact experiments are performed using the JC material model constants and good agreement is obtained between the simulation results and the experimental data, which further proves the ability of the model to describe the constitutive model of Ta-W alloys.

\section{References}

1 Kock W, Paschen P. JOM[J], 1989, 41(10): 33

2 Zhong W Z, Song S C, Xie R Z et al. High Pressure Physics[J], 2010, 24(1): 49 (in Chinese)

3 Nemat-Nasser S, Rajeev K. International Journal of Plasticity[J], 2001, 17: 1351

4 Nemat-Nasser S, Isaacs J B. Acta Materialia[J], 1997, 45(3): 907

5 Chen S R, Gray G T. Metallurgical and Materials Transactions A[J], 1996, 27(10): 2994

6 Peng J X, Li D H. Chinese Journal of High Pressure Physics[J], 2001, 15(2): 146 (in Chinese)

7 Chen S R, Gray III G T, Bingert S R. LANL Report, LA-UR[R], 1996, 96-0602

8 Gray III G T. Annual Review of Materials Research[J], 2012, 42: 285

9 Zhang T J, Zhang D Y, Ding X. Rare Metal Materials and Engineering [J], 1996, 25(4): 5 (in Chinese)

10 Johnson G R, Cook W H. Proceedings of the 7th International Symposium on Ballistics[C], The Netherlands, 1983, 21: 541

11 Zerilli F J, Armstrong R W. Journal of Applied Physics[J], 1987, 61(5): 1816

12 Steinberg D J, Cochran S G, Guinan M W. Journal of Applied Physics[J], 1980, 51(3): 1498

13 Peng J X, Li Y L, Li D H. Explosion and Shock Waves[J], 2003, 23(2): 183 (in Chinese)

14 Bai R, Zhang X M, Hu Z W et al. Rare Metal Materials and 
Engineering [J], 2008, 37(9): 1526 (in Chinese)

15 Plunkett B, Cazacu O, Lebensohn R A et al. International Journal of Plasticity[J], 2007, 23: 1001

16 Brünig M, Driemeier L. International Journal of Plasticity[J], 2007, 23: 1979

17 Lopatnikov S L, Gama B A et al. Composite Structures[J], 2003, 61(1): 61

18 Teng $\mathrm{X}$, Wierzbicki $\mathrm{T}$, Hiermaier $\mathrm{S}$ et al. International Journal of Solids and Structures[J], 2005, 42: 2929

19 Xiao X K, Zhang W, Wei G et al. Materials and Design[J], 2010, 31: 4913
20 Xiao X K, Zhang W, Wei G et al. Materials and Design[J], 2011, 32: 2663

21 Rakvåg K G, Børvik T, Westermann I et al. Materials and Design[J], 2013, 51: 242

22 Rakvåg K G, Børvik T, Hopperstad O S. International Journal of Solids and Structures[J], 2014, 51: 808

23 Chen X W, Chen G, Zhang F J. Experimental Mechanics $[\mathrm{J}]$, 2008, 48: 335

24 Brar N S, Joshi V S, Harris B W. Shock Compression of Condensed Matter[J], 2007(4): 627

\section{钽铇合金动态力学行为及其本构模型研究}

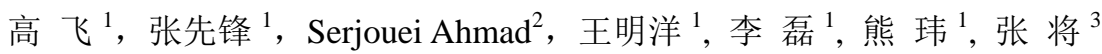

(1. 南京理工大学, 江苏 南京 210094)

(2. 南洋理工大学, 新加坡 639798)

(3. 中国兵器科学研究院宁波分院, 浙江 宁波 315103)

摘 要: 对 2 种钽铇合金（Ta-2.5W 和 Ta-10W, 铇的质量分数分别为 $2.5 \%$ 和 $10 \%$ ）的准静态和动态变形行为进行了系统研究。根据 准静态压缩实验、霍普金森压杆 (SHPB) 实验结果, 表明 2 种钽铇合金的流动应力对加载应变率和铇的含量较为敏感, 并拟合得到了 2 种钽铇合金的 JC 本构模型参数。其次, 为验证本构模型的合理性, 开展了泰勒撞击实验和数值模拟研究, 应变率范围为 $10^{3} \sim 10^{4} \mathrm{~s}^{-1}$, 数值模拟得到的泰勒杆侧轮廓与撞击端面轮廓与实验吻合较好。最后, 为研究钽铇合金变形后的细观特性, 对杆件进行了光学显微照 片分析。本研究方法与结果可为材料本构关系的确定提供借鉴。

关键词：钽铇合金；霍普金森压杆；动态行为；Taylor 冲击；本构模型

作者简介: 高 飞, 男, 1990 年生, 博士生, 南京理工大学机械工程学院, 江苏 南京 210094, 电话: 025-84315149, E-mail: gaofei5257@163.com 